\title{
BMJ Open Vortioxetine treatment for generalised anxiety disorder: a meta-analysis of anxiety, quality of life and safety outcomes
}

\author{
Bin Qin, ${ }^{1}$ Guangsu Huang, ${ }^{2}$ Qian Yang, ${ }^{2}$ Mingjun Zhao, ${ }^{3}$ Hong Chen, ${ }^{2}$ Wen Gao, ${ }^{2}$ \\ Mingxiu Yang ${ }^{2}$
}

To cite: Qin B, Huang G, Yang Q, et al. Vortioxetine treatment for generalised anxiety disorder: a meta-analysis of anxiety, quality of life and safety outcomes. BMJ Open 2019;9:e033161. doi:10.1136/ bmjopen-2019-033161

- Prepublication history and additional material for this paper are available online. To view please visit the journal (http:// dx.doi.org/10.1136/bmjopen2019-033161).

$\mathrm{BQ}, \mathrm{GH}$ and $\mathrm{QY}$ contributed equally.

Received 23 July 2019 Revised 17 October 2019 Accepted 24 October 2019

A) Check for updates

(C) Author(s) (or their employer(s)) 2019. Re-use permitted under CC BY-NC. No commercial re-use. See rights and permissions. Published by BMJ.

${ }^{1}$ Department of Neurology, Affiliated Liuzhou General Hospital of Guangxi University of Science and Technology, Liuzhou, China

2Department of Neurology, Affiliated Liuzhou General Hospital of Guangxi University of Science and Technology, Liuzhou, China

${ }^{3}$ Department of Pharmacy, The Second Affiliated Hospital of Xinxiang Medical University, Xinxiang, China

Correspondence to Professor Mingxiu Yang; Izrmyyymx@126.com

\section{ABSTRACT}

Objectives The aim of this study was to investigate the efficacy, tolerability, safety, and impact on quality of life (QoL) and functional status of vortioxetine treatment for patients with generalised anxiety disorder (GAD) by performing a meta-analysis of randomised controlled trials (RCTs).

Design Systematic review and meta-analysis. Data sources Data mining was conducted in January 2019 across PubMed, EMBASE, PsycINF0, Cochrane Central Register of Controlled Trials Cochrane Library, Web of science and ClinicalTrials.gov.

Eligibility criteria for selecting studies All published RCTs, which assessed the effect of vortioxetine treatment for patients with GAD when compared with a placebo group, were included.

Data extraction and synthesis Relevant data were extracted and synthesised narratively. Results were expressed as standardised mean differences or ORs with $95 \%$ Cls.

Results Our meta-analysis showed that multiple doses (2.5, 5 and $10 \mathrm{mg} /$ day) of vortioxetine did not significantly improve the response rates, compared with placebo (OR $1.16,95 \% \mathrm{Cl} 0.84$ to $1.60, \mathrm{p}=0.38 ;$ OR $1.41,95 \% \mathrm{Cl}$ 0.82 to $2.41, \mathrm{p}=0.21$; and $\mathrm{OR} 1.05,95 \% \mathrm{Cl} 0.76$ to 1.46 , $\mathrm{p}=0.75)$. Moreover, there was no statistically significant difference regarding the remission rates, discontinuation for any reason rates, discontinuation due to adverse events rates, Short-Form 36 Health Survey scores or Sheehan Disability Scale scores between administration of multiple doses (2.5, 5 and $10 \mathrm{mg} /$ day) of vortioxetine and placebo. Conclusions Although our results suggest that vortioxetine did not improve the GAD symptoms, QoL and functional status impairment of patients with $G A D$, it was safe and well tolerated. Clinicians should interpret and translate our data with caution, as the meta-analysis was based on a limited number of RCTs.

\section{INTRODUCTION}

Generalised anxiety disorder (GAD) is a common, chronic, costly and disabling mental disorder that is marked by persistent anxiety and worry, and multiple psychological and physical symptoms. ${ }^{12}$ It is also characterised by various psychological and
Strengths and limitations of this study

- This systematic review and meta-analysis provides evidence for the efficacy, tolerability and safety of vortioxetine in treatment of patients with generalised anxiety disorder.

- Improvement of quality of life and functional status impairment were also evaluated to judge the patients' well-being of vortioxetine.

- Strong and reliable methodological and statistical procedures were applied.

- Due to the short-term follow-up in the evaluated studies, the long-term effect was not studied.

somatic complaints, such as autonomic arousal, restlessness, fatigue, problems with concentration, irritability and sleeplessness. ${ }^{1}$ The estimated 1-year prevalence rate of GAD is between $1.2 \%$ and $1.9 \%$, and the lifetime prevalence is between $4.3 \%$ and $5.9 \% .^{2}{ }^{3}$ Since most patients are still affected for 6-12 years after diagnosis, GAD is usually considered a chronic disorder and a major burden on the individual, their family and healthcare services. ${ }^{24}$ Anxiety is a common comorbidity of chronic medical diseases, including atopic dermatitis, asthma, rheumatoid arthritis, lupus and stroke. Anxiety has a negative impact on the quality of life (QoL) of patients suffer from chronic diseases. ${ }^{56}$

Vortioxetine is a multimodal antidepressant that was approved for the treatment of major depressive disorder (MDD), by the US Food and Drug Administration (FDA) in September 2013. Vortioxetine's mechanism of action is related to its multimodal activity, which combines two pharmacological properties: direct modulation of receptor activity and inhibition of the 5-HT transporter, and thereby with potential benefits in the treatment of major depressive episode and, probably, GAD and anxiety disorders. ${ }^{7}$ In 
addition, vortioxetine causes a significant increase in the hippocampal brain-derived neurotrophic factors levels as compared with selective serotonin reuptake inhibitors. ${ }^{8}$ Several meta-analyses have proved the efficacy of vortioxetine in treatment of MDD. ${ }^{9-11}$ A recent scientometric analysis reported that the popularity of vortioxetine is rising. ${ }^{12}$ Clinical trials evaluating its efficacy for the treatment of GAD, with doses up to $10 \mathrm{mg}$ /day, have also yielded some interesting findings. ${ }^{13-16}$ Moreover, as vortioxetine has been proven to be efficient in the treatment of MDD comorbid with GAD, it is possible that it constitutes an effective treatment for GAD alone, as well. ${ }^{17}$

Interestingly, the efficacy of vortioxetine therapy in reducing anxiety symptom severity in GAD is summarised in two previous meta-analyses. ${ }^{18} 19$ Both reviews analysed its efficacy only in terms of symptom severity on the underlying continuous rating scales, and did not assess dichotomous outcomes of response and remission rates. However, a recent meta-analysis examined the efficacy of multiple doses of vortioxetine in terms of dichotomous response outcomes, and the results showed no significant improvement in the outcomes of treating GAD with vortioxetine compared with treating GAD with placebo. ${ }^{20}$ The efficacy was only assessed using continuous rating scales or dichotomous response; thus, the authors of these meta-analyses and of a relevant narrative review noted that a comprehensive summary of efficacy data is missing. Further, both these reviews only provided an assessment of efficacy and safety outcomes, and did not include important outcomes of patient-focused assessments, such as assessment of functional impairment and QoL. Currently, there is growing interest in assessing the QoL and functional status impairment in patients with psychological disorders. ${ }^{21}{ }^{22}$ In addition, the importance of including such assessments in evaluations of the influence of psychological disorders and their treatment is widely recognised. ${ }^{23-26}$ Our previous network meta-analysis concluded that risperidone and aripiprazole improved the QoL of patients with treatment-resistant depression. ${ }^{27}$ Despite the growing interest in the field, studies addressing the impairment of QoL and functional status caused by anxiety disorders have progressed slowly. ${ }^{28}$ Moreover, GAD is an important public mental health problem that causes poor QoL and functional status impairment, ${ }^{23}$ with substantial impact on work and social roles. ${ }^{29}$ Thus, the outcome of posttreatment QoL assessments is recognised as an important measure of treatment efficacy for patients with GAD. ${ }^{30}$

The assessment of antianxiety therapy benefits on QoL and functional status impairment in patients with GAD is becoming increasingly common in clinical studies, mainly because, both aspects are important for the patients' overall well-being and recovery. Currently, the direct effect of vortioxetine treatment on QoL and functional status impairment in patients with GAD is unclear. Therefore, this meta-analysis was conducted to provide a comprehensive estimate of the efficacy, safety, and improving QoL and functional status impairment profiles of vortioxetine in treatment of GAD.

\section{METHODS}

All steps of this review were performed in strict accordance with the Cochrane Handbook for Systematic Reviews of Interventions. ${ }^{31}$ The Preferred Reporting Items for Systematic Reviews and Meta-Analyses statement guidelines were followed during the meta-analysis and preparation of this review. ${ }^{32}$

\section{Search strategy}

As of January 2019, we searched PubMed, EMBASE, PsycINFO, Cochrane Central Register of Controlled Trials (Cochrane Library), Web of science and ClinicalTrials. gov (www.clinicaltrials.gov). Search terms included "vortioxetine OR Lu AA21004" OR Brintellix" AND "anxiety OR anxiety disorder OR anxiety disorders OR mood disorder OR mood disorders" (online supplementary table 1). No language or time restrictions were applied. Titles and abstracts were screened by two independent reviewers, before full texts of potentially relevant articles were retrieved for further evaluation. The decision to include a study was then made by two independent reviewers (QB and $\mathrm{WG})$, after full-text review. The reference lists of included articles were further hand-searched to identify additional relevant articles.

\section{Eligibility criteria and study selection}

We included all clinical trials meeting the following criteria: (1) randomised controlled trials (RCTs) involving patients ( $\geq 18$ years old) primarily diagnosed with GAD, according to the criteria of the Diagnostic and Statistical Manual of Mental Disorders, fourth edition, text revision and (2) RCTs comparing outcomes in efficacy, QoL and functional impairment between vortioxetine and placebo. We excluded (1) retrospective and observational studies; (2) non-human studies; (3) theses and conference abstracts; and (4) studies including patients who had any concurrent psychiatric disorders with GAD or any prior history of psychiatric disorders, such as manic or hypomanic episodes, schizophrenia or substance use disorders. Eligibility screening was performed in two steps, each by two independent reviewers ( $\mathrm{QB}$ and $\mathrm{WG}$ ): (1) title and abstract screening for relevance to the study objective and (2) fulltext screening for eligibility for a meta-analysis. Conflicts were resolved by the opinion of a third reviewer (MY).

\section{Outcomes}

Efficacy measures

Response was defined across studies as a $50 \%$ improvement of the Hamilton Anxiety Rating Scale (HAM-A) total score from baseline to the end point. Remission was defined as an HAM-A total score of $\leq 7$ at the study end point. The continuous measure of efficacy was the mean change from baseline in total scores on the HAM-A, as defined by the individual study.

\section{Safety and tolerability measures}

Data on the discontinuation for any reason (tolerability) and the numbers of discontinuation due to adverse events (AEs) (safety) were included in the analysis. 
QoL and functioning measures

QoL can be assessed by study-designed questionnaires and disease-specific or generic instruments. These instruments assess an individual's physical, emotional, psychological and social health. ${ }^{33}$ We selected the Short-Form 36 Health Survey (SF-36) ${ }^{35}$ scores as the outcome indicator for QoL to preserve sufficient homogeneity for meta-analysis, because this instrument is used to measure QoL for the GAD population in many studies. Studies were excluded if the QoL outcome was reported by the other rating scales. The Sheehan Disability Scale (SDS), ${ }^{36}$ a reliable, valid, brief, self-report scale that assesses disability in work, social and family life, is the only measure of functional impairment employed by the trials included in this meta-analysis.

\section{Data extraction}

Two independent reviewers (QB and WG) extracted the following data from the included studies: (1) baseline characteristics of enrolled patients, (2) general characteristics of the study design, (3) information on efficacy, safety, tolerability, QoL and functioning outcome. Data were summarised by one investigator and checked by a second reviewer. Any discrepant data were, again, examined by a third reviewer (MY), to ensure accurate data were obtained.

\section{Risk of bias assessment}

The risk of bias within each study was assessed by two independent reviewers ( $\mathrm{QB}$ and WG) using the Cochrane Risk of Bias assessment tool, as described in the Cochrane Handbook for Systematic Reviews of Interventions 5.1.0. ${ }^{31}$ This tool classifies the studies as having low, unclear or high risk of bias across six domains: sequence generation, allocation concealment, blinding, missing data, selective reporting and other biases.

\section{Data analysis}

The meta-analysis was conducted using RevMan V.5.3 software (Cochrane Collaboration, London, UK) and Stata V.13.0 software (StataCorp). ORs and 95\% CIs were used to assess binary outcomes, such as response, remission rates, as well as discontinuation for any reason rates. In addition, we converted continuous data to standardised mean differences (SMDs) and 95\% CIs. The statistical heterogeneity among trials was measured by $Q$ statistics and the $\mathrm{I}^{2}$ test. Higher $\mathrm{I}^{2}$ values indicate greater heterogeneity, with $\mathrm{I}^{2}$ values of 25,50 and $75 \%$ signifying mild, moderate and high heterogeneity, respectively. ${ }^{37} 38$ Based on heterogeneity, data were pooled to estimate the overall effect of all the interventions by random-effect or fixed-effect modelling. Fixed-effect models assume that the population effect sizes are the same for all studies. In contrast, random-effects model attempted to generalise findings beyond the included studies by assuming that the selected studies are random samples from a larger population. ${ }^{39}$ Sensitivity analyses were performed to test the impact robustness of every single study on the overall results. Publication bias could be assessed by visual inspection of a funnel plot, and the Egger test was also used to evaluate publication biases. However, according to Egger et al, assessing publication bias using the funnel plot-based methods is not reliable when fewer than 10 pooled studies are used in the direct comparison. ${ }^{40}$

\section{Patient and public involvement}

Patients or the public were not involved in the conceptualisation or carrying out of this research.

\section{RESULTS}

\section{Search results}

We identified 94 references from the electronic literature search. After screening the titles and abstracts, 85 were excluded because they failed to meet the inclusion criteria. By reading the full text of the remaining nine articles, five more were excluded: one study included patients with depression, one study focused on vortioxetine in the prevention of relapse of GAD, another one constituted a conference abstract and did not provide treatment outcomes, and two studies were eliminated because they were review articles. Ultimately, only four studies that fully satisfied the pre-established inclusion criteria of this meta-analysis were included (see online supplementary figure 1). ${ }^{13-16}$

\section{Study characteristics}

Four included studies were published between 2012 and 2014 (table 1). ${ }^{13-16}$ The collective patient population comprised 1074 individuals in the vortioxetine group and 613 individuals in the placebo group. The administered doses of vortioxetine were $2.5,5$ and $10 \mathrm{mg} /$ day. The mean age of participants ranged from 36.8 to 45.3 years. All studies were characterised by a preponderance of female subjects, with proportions ranging from $60 \%$ to $70 \%$. The main characteristics of these studies are presented in table 1 .

\section{Study quality}

The risks of bias in each study is summarised in online supplementary figure 2. All studies claimed randomisation and three articles described the method of random sequence generation (random number table, computer generated). Three trials provided information that allowed us to assess whether an adequate concealment of the allocation procedure was used. All studies reported the blinding of participants. Therefore, all trials were deemed to have a mild-to-moderate risk of bias.

\section{Efficacy}

In terms of response, a total of four studies were included in the analysis; the overall ORs observed for groups treated with multiple doses $(2.5,5$, and $10 \mathrm{mg} /$ day) of vortioxetine compared with placebo were 1.16 (95\% CI 0.84 to $1.60, \mathrm{Z}=0.89, \mathrm{p}=0.38), 1.41$ (95\% CI 0.82 to $2.41, \mathrm{Z}=1.25$, $\mathrm{p}=0.21$ ) and 1.05 (95\% CI 0.76 to $1.46, \mathrm{Z}=0.32, \mathrm{p}=0.75)$, respectively (figure 1 ). The results showed that there was no statistically significant difference in the response rates among the vortioxetine and placebo groups. In addition, 
Table 1 Description of included studies

\begin{tabular}{|c|c|c|c|c|c|c|}
\hline Study & Patients N & Age (mean, SD) & Sex (male, $n, \%$ ) & Interventions & $\begin{array}{l}\text { Duration } \\
\text { (weeks) }\end{array}$ & $\begin{array}{l}\text { Key inclusion } \\
\text { criteria for GAD }\end{array}$ \\
\hline Bidzan et al (2012) $)^{13}$ & $\begin{array}{l}\text { T: } 150 \\
\text { C: } 151\end{array}$ & $\begin{array}{l}\text { T: } 45.0(14.1) ; \\
\text { C: } 45.3(13.5)\end{array}$ & $\begin{array}{l}\text { T: } 47(31.3) \\
\text { C: } 58(38.4)\end{array}$ & $\begin{array}{l}\text { T: vtx }(5 \mathrm{mg} / \mathrm{d}) \text {; } \\
\text { C: placebo }\end{array}$ & 8 & $\begin{array}{l}\text { DSM-IV-TR, } \\
\text { HAM-A } \geq 20\end{array}$ \\
\hline $\begin{array}{l}\text { Mahableshwarkar et al } \\
(2014 a)^{14}\end{array}$ & $\begin{array}{l}\text { T: } 152,152 ; \\
\text { C: } 153\end{array}$ & $\begin{array}{l}\text { T: } 40.8(13.8)^{\prime} \\
43.3(15.0) ; \\
\text { C: } 39.5(13.5)\end{array}$ & $\begin{array}{l}\text { T: } 49 \text { (32.2), } \\
56(36.8) ; \\
\text { C: } 48(31.4)\end{array}$ & $\begin{array}{l}\text { T: vtx } 2.5 \mathrm{mg} / \mathrm{d}, \mathrm{vtx} \\
10 \mathrm{mg} / \mathrm{d} \text {; } \\
\text { C: placebo }\end{array}$ & 8 & $\begin{array}{l}\text { DSM-IV-TR, } \\
\text { HAM-A } \geq 20\end{array}$ \\
\hline Rothschild et al (2012) ${ }^{16}$ & $\begin{array}{l}\text { T: } 152 ; \\
\text { C: } 152\end{array}$ & $\begin{array}{l}\text { T: } 41.0 \text { (14.05); } \\
\text { C: } 41.4 \text { (12.81) }\end{array}$ & $\begin{array}{l}\text { T: } 49 \text { (32.2); } \\
\text { C: } 55 \text { (36.2) }\end{array}$ & $\begin{array}{l}\text { T: vtx } 5 \mathrm{mg} / \mathrm{d} \text {; } \\
\text { C: placebo }\end{array}$ & 8 & $\begin{array}{l}\text { DSM-IV-TR, } \\
\text { HAM-A } \geq 20\end{array}$ \\
\hline
\end{tabular}

C, control group; DSM-IV-TR, Diagnostic and Statistical Manual of Mental Disorders 4th edition Text Revision; GAD, generalised anxiety disorder; HAM-A, Hamilton Anxiety Rating; mg/d, mg/day; T, treatment group; vtx, vortioxetine.

there was no statistically significant difference for the remission rates in multiple doses $(2.5,5$ and $10 \mathrm{mg} /$ day $)$ of vortioxetine compared with placebo (figure 2 ).

Pooled effect sizes for the mean change from baseline in total scores on the HAM-A are provided in figure 3. The overall SMDs observed for the groups treated with multiple doses $(2.5,5$ and $10 \mathrm{mg} /$ day) of vortioxetine compared with the placebo were $-0.13(95 \% \mathrm{CI}-0.29$ to $0.03, \mathrm{Z}=1.56, \mathrm{p}=0.12),-0.15$ (95\% CI -0.48 to $0.18, \mathrm{Z}=0.87$, $\mathrm{p}=0.38)$ and $-0.08(95 \% \mathrm{CI}-0.24$ to $0.08, \mathrm{Z}=1.01, \mathrm{p}=0.31)$, respectively. The results also showed that there was no statistically significant difference in the mean change from baseline in total scores on the HAM-A among the vortioxetine and placebo groups.

\section{Tolerability and safety}

No significant difference was observed between the vortioxetine and placebo groups in terms of the likelihood of
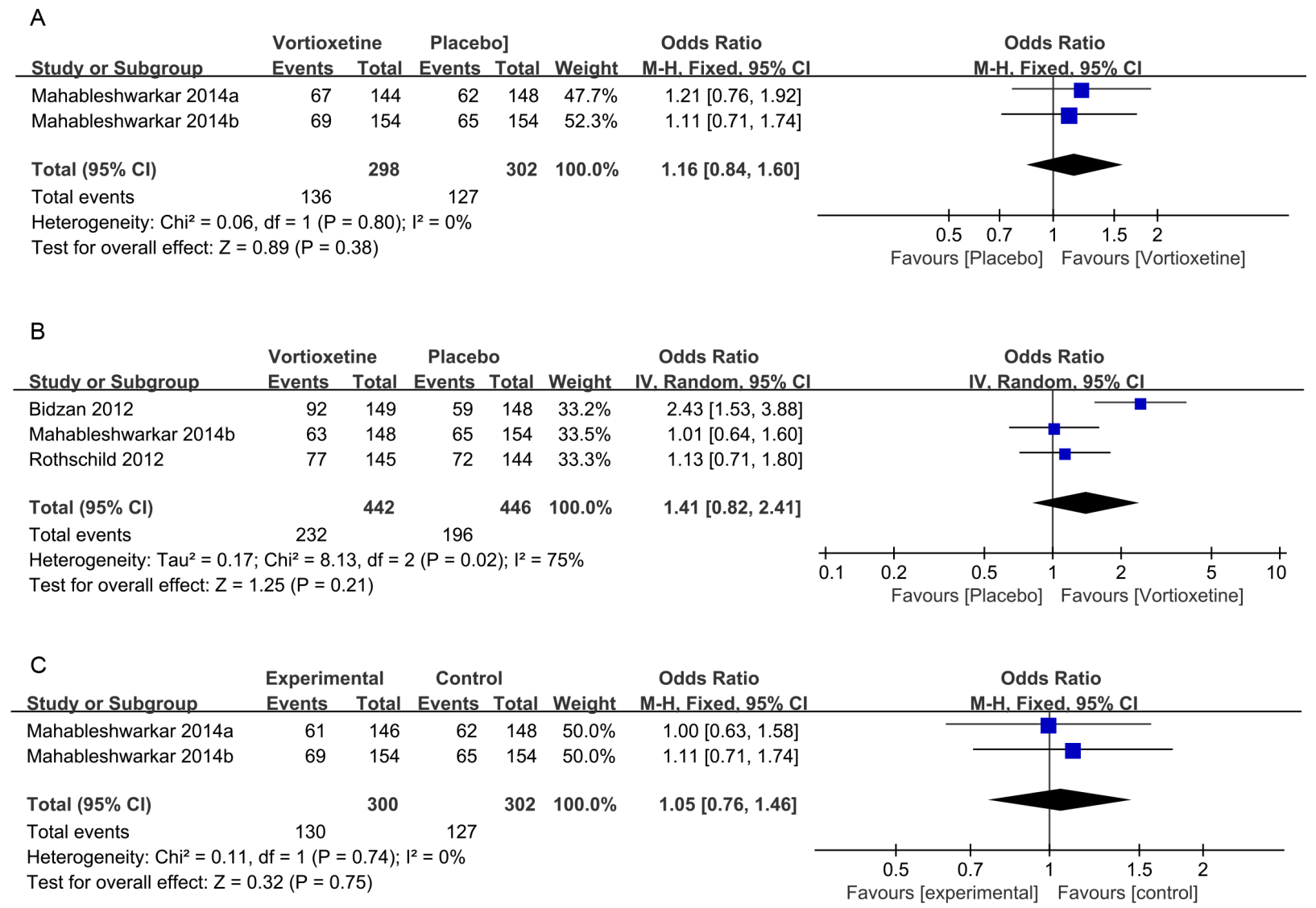

Figure 1 ORs and $95 \%$ Cls of the individual studies and the pooled data, comparing the response rates between the vortioxetine-treated and placebo groups. (A) $2.5 \mathrm{mg} /$ day vortioxetine vs placebo, (B) $5 \mathrm{mg} /$ day vortioxetine versus placebo and (C) $10 \mathrm{mg} /$ day vortioxetine versus placebo. M-H, Mantel-Haenszel; IV, Inverse Variance. 
A
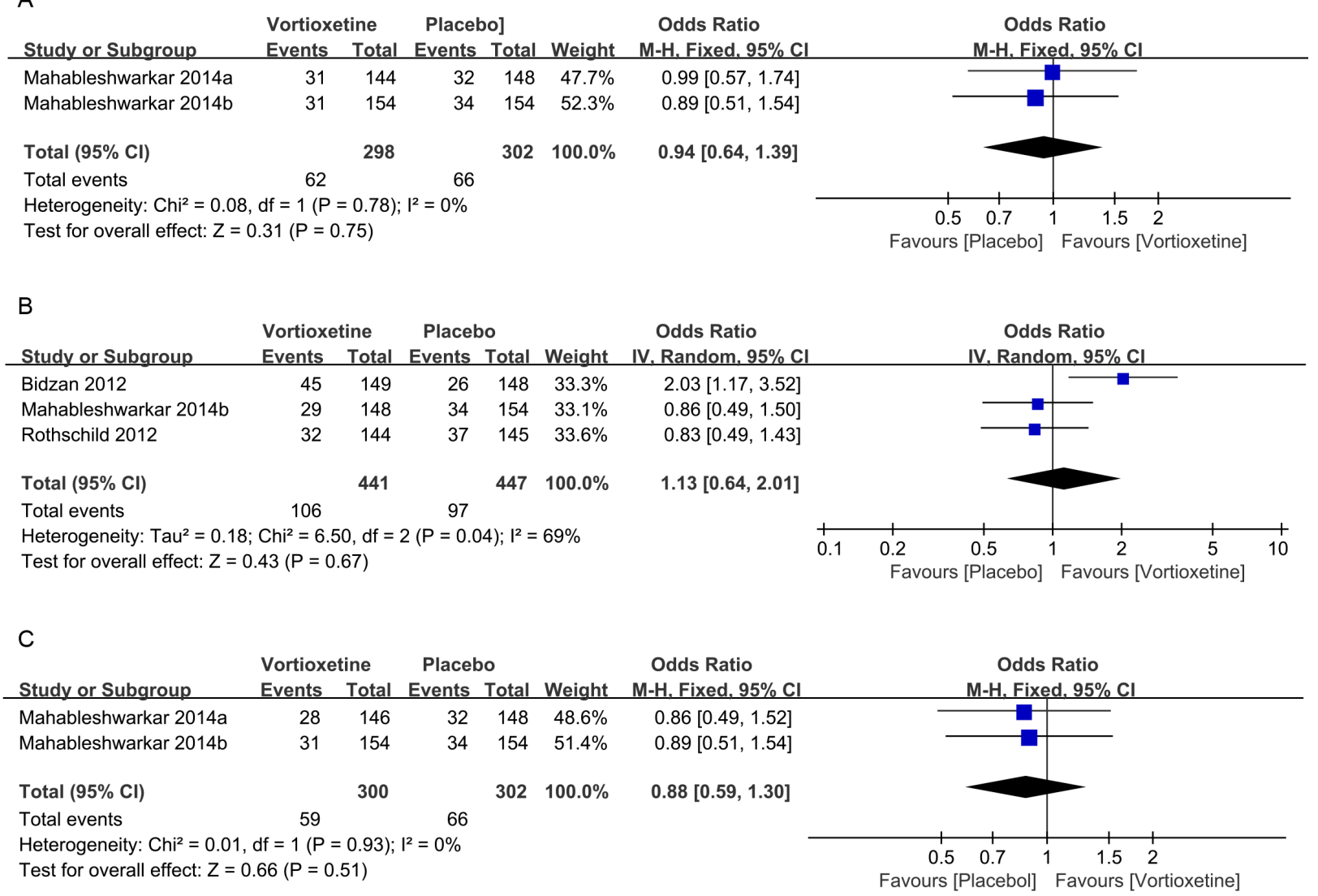

Figure 2 ORs and $95 \% \mathrm{Cls}$ of the individual studies and the pooled data, comparing the remission rates between the vortioxetine and placebo groups. (A) $2.5 \mathrm{mg} /$ day vortioxetine versus placebo, (B) $5 \mathrm{mg} /$ day vortioxetine versus placebo and (C) $10 \mathrm{mg} /$ day vortioxetine versus placebo. $\mathrm{M}-\mathrm{H}$, Mantel-Haenszel; IV, Inverse Variance.

discontinuation for any reason (tolerability). The overall ORs observed for the groups treated with multiple doses (2.5, 5 and $10 \mathrm{mg} /$ day) of vortioxetine compared with the placebo-treated group were 1.03 (95\% CI 0.71 to $1.47, \mathrm{Z}=0.14, \mathrm{p}=0.89$ ), 0.87 (95\% CI 0.63 to $1.20, \mathrm{Z}=0.87$, $\mathrm{p}=0.38$ ) and 1.06 (95\% CI 0.74 to $1.52, \mathrm{Z}=0.32, \mathrm{p}=0.75)$, respectively (online supplementary figure 3 ). Additionally, there was no statistically significant difference in the discontinuation due to AEs (safety) between the groups treated with multiple doses $(2.5,5$ and $10 \mathrm{mg}$ /day) of vortioxetine and the group treated with placebo (online supplementary figure 4 ).

\section{QoL and functional status results}

Three studies in this analysis reported SF-36 scores as the outcome measure of QoL. The overall SMDs of groups treated with multiple doses $(2.5,5$ and $10 \mathrm{mg} /$ day $)$ of vortioxetine compared with placebo were 0.12 (95\% CI -0.11 to $0.35, \mathrm{Z}=1.04, \mathrm{p}=0.30), 0.22$ ( $95 \% \mathrm{CI}-0.12$ to 0.56 , $\mathrm{Z}=1.26, \mathrm{p}=0.21)$ and $0.09(95 \% \mathrm{CI}-0.14$ to $0.32, \mathrm{Z}=0.75$, $\mathrm{p}=0.45$ ), respectively (figure 4 ). The results showed that there was no statistically significant difference in SF-36 scores among the different groups. SDS scores were available for all four studies included in this analysis. The overall SMDs for the groups treated with multiple doses $(2.5,5$ and $10 \mathrm{mg}$ /day) of vortioxetine compared with placebo were -0.11 (95\% CI -0.30 to $0.08, \mathrm{Z}=1.09$, $\mathrm{p}=0.28),-0.10(95 \% \mathrm{CI}-0.27$ to $0.06, \mathrm{Z}=1.27, \mathrm{p}=0.21)$ and -0.20 (95\% CI -0.39 to $0.00, \mathrm{Z}=2.00, \mathrm{p}=0.05$ ), respectively (figure 5). The results showed that there was no statistically significant difference in SDS among the different groups.

\section{Publication bias}

The Egger test showed no significant difference main outcomes, indicating no publication bias.

\section{DISCUSSION}

In this meta-analysis of four randomised trials studying vortioxetine as a treatment for GAD, we found that vortioxetine (2.5, 5 and $10 \mathrm{mg}$ once-daily doses) did not significantly improve GAD symptoms, QoL and functional status compared with a placebo treatment. However, vortioxetine might be safe and well tolerated in this patient population. Our findings have some clinical implications for comprehensively understanding the risk-benefit profiles of vortioxetine treatment for GAD.

Our results are not consistent with those of the previous meta-analysis conducted by Pae $e t a l$, as that study found that vortioxetine was significantly more effective than the placebo. ${ }^{18}$ In their study, they only performed the analysis of mean change from baseline in total scores on the HAM-A, and included all randomised subjects. However, 
A

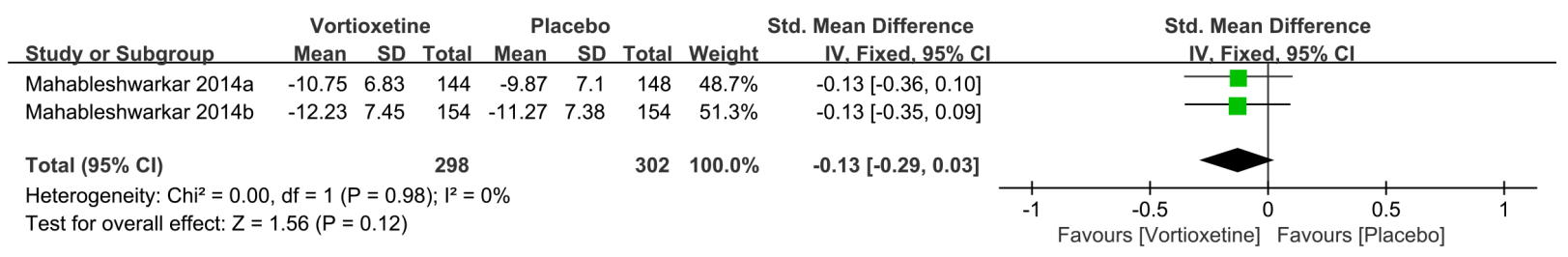

\begin{tabular}{|c|c|c|c|c|c|c|c|}
\hline \multirow[b]{2}{*}{ Study or Subgroup } & \multicolumn{3}{|c|}{ Vortioxetine } & \multicolumn{3}{|c|}{ Placebo } & \multirow[b]{2}{*}{ Weigh } \\
\hline & Mean & SD & Total & Mean & SD & Total & \\
\hline Bidzan 2012 & -14.3 & 7.81 & 128 & -10.49 & 7.75 & 126 & $33 .($ \\
\hline Mahableshwarkar 2014b & -11.57 & 7.37 & 148 & -11.27 & 7.38 & 154 & \\
\hline Rothschild 2012 & -12.57 & 7.19 & 124 & -13.16 & 6.96 & 113 & \\
\hline Total $(95 \% \mathrm{Cl})$ & & & 400 & & & 393 & 100. \\
\hline $\begin{array}{l}\text { Heterogeneity: } \mathrm{Tau}^{2}=0 . \\
\text { Test for overall effect: } Z\end{array}$ & $\begin{array}{l}\mathrm{Chi}^{2}= \\
87(\mathrm{P}=\end{array}$ & $\begin{array}{l}1.16, \\
0.38)\end{array}$ & $f=2$ & $=0$. & t); I & $82 \%$ & \\
\hline
\end{tabular}

Std. Mean Difference Std. Mean Difference

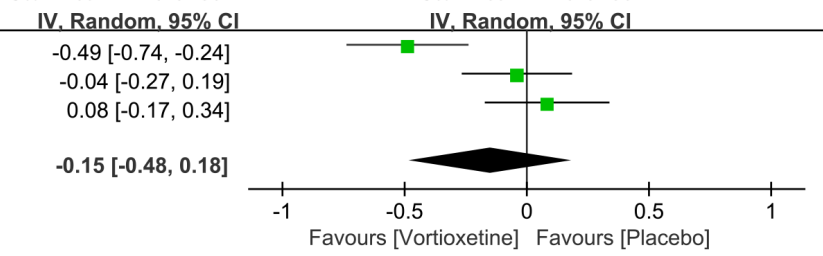

C

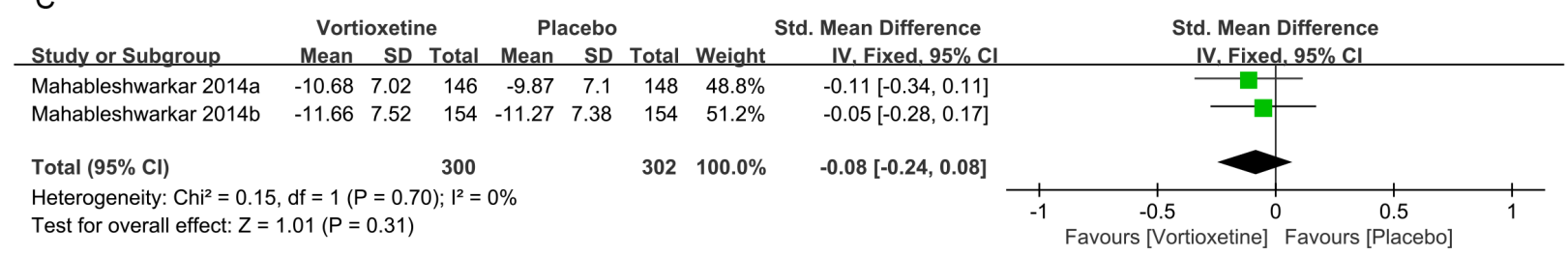

Figure 3 Standardised mean differences and $95 \% \mathrm{Cls}$ of the individual studies and the pooled data, comparing the mean change from baseline in total scores on the HAM-A, between the vortioxetine and placebo groups. (A) $2.5 \mathrm{mg} / \mathrm{day}$ vortioxetine versus placebo, (B) $5 \mathrm{mg} /$ day vortioxetine versus placebo and (C) $10 \mathrm{mg} /$ day vortioxetine versus placebo. HAM-A, Hamilton Anxiety Rating Scale; M-H, Mantel-Haenszel; IV, Inverse Variance.

our meta-analysis was separately conducted according to the doses of vortioxetine, and we assessed the efficacy in terms of mean change from baseline in total scores on the HAM-A, response rates and remission rates. Doses of vortioxetine may be clinically important factors for its efficacy in patients with GAD. Thus, the results of our meta-analysis were more reliable and stable. Moreover, a recent meta-analysis showed that there was no statistically
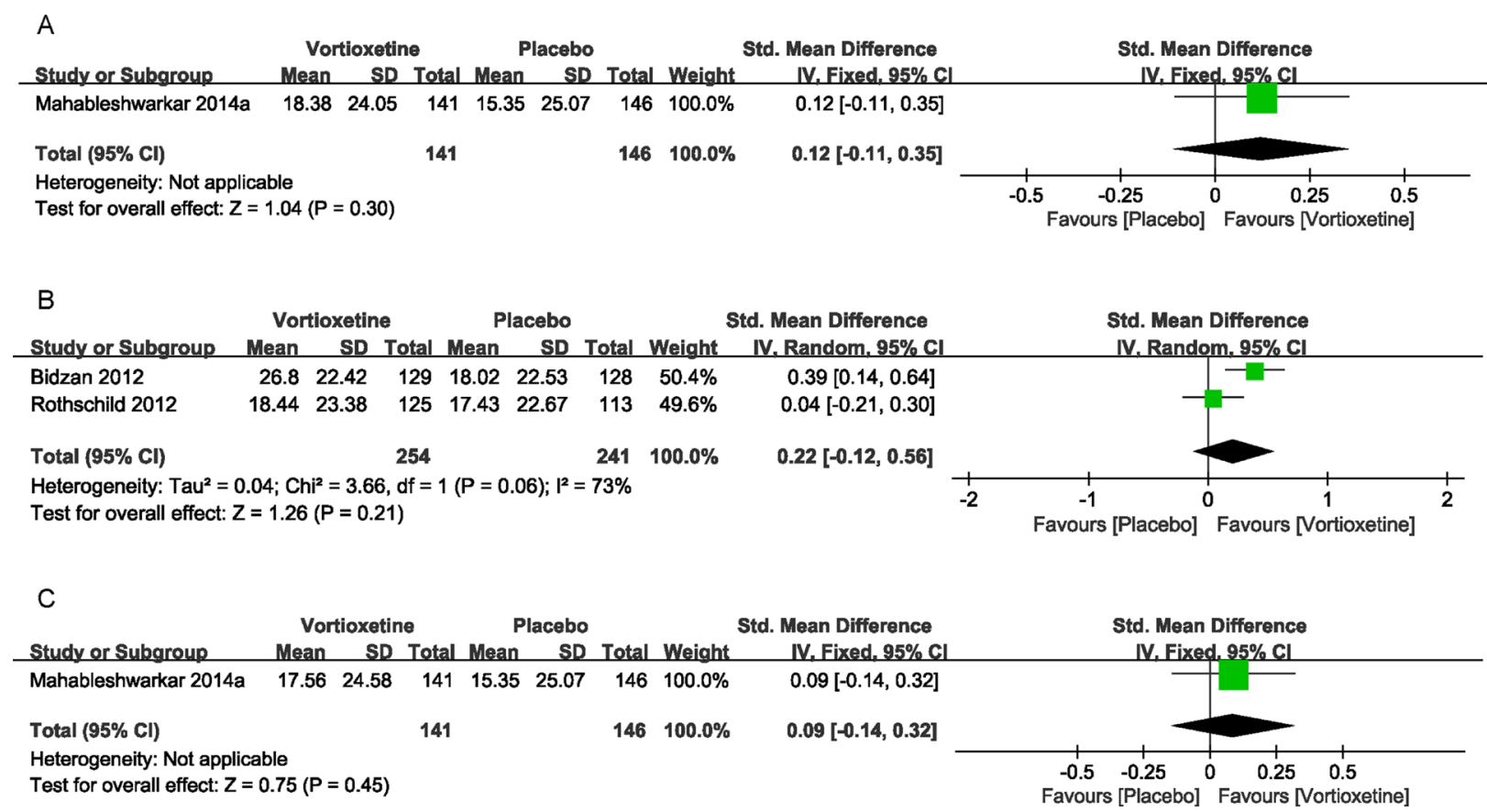

Figure 4 Standardised mean differences and $95 \% \mathrm{Cls}$ of the individual studies and the pooled data, comparing the ShortForm 36 Health Survey scores between the vortioxetine and placebo groups. (A) $2.5 \mathrm{mg} /$ day vortioxetine versus placebo, (B) $5 \mathrm{mg} /$ day vortioxetine versus placebo and (C) $10 \mathrm{mg} /$ day vortioxetine versus placebo. M-H, Mantel-Haenszel; IV, Inverse Variance. 
A

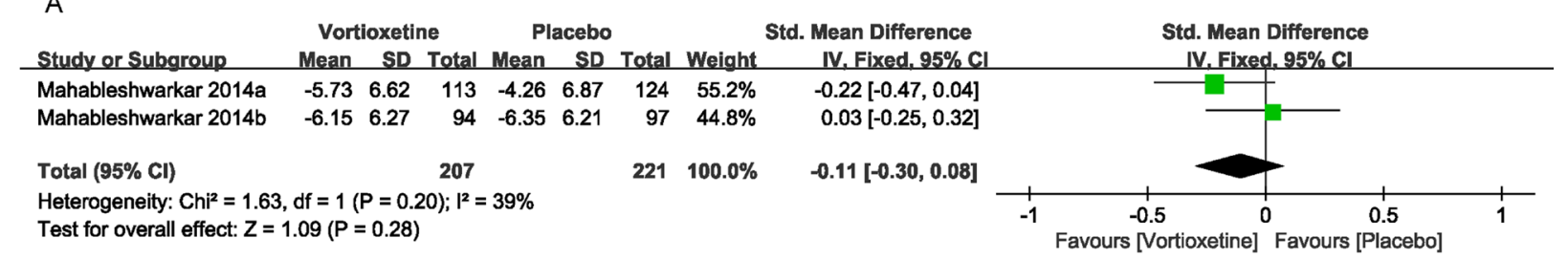

B

\begin{tabular}{|c|c|c|c|c|c|c|c|c|c|c|c|}
\hline \multirow[b]{2}{*}{ Study or Subgroup } & \multicolumn{3}{|c|}{ Vortioxetine } & \multicolumn{3}{|c|}{ Placebo } & \multicolumn{2}{|r|}{ Std. Mean Difference } & \multirow{2}{*}{\multicolumn{3}{|c|}{$\begin{array}{c}\text { Std. Mean Difference } \\
\text { IV. Fixed, } 95 \% \mathrm{Cl}\end{array}$}} \\
\hline & Mean & SD & Total & Mean & SD & Total & Weight & IV. Fixed. $95 \% \mathrm{Cl}$ & & & \\
\hline Bidzan 2012 & -8.1 & 6.63 & 102 & -6.14 & 6.59 & 109 & $35.4 \%$ & $-0.30[-0.57,-0.02]$ & & & \\
\hline Mahableshwarkar 2014b & -6.68 & 6.26 & 95 & -6.35 & 6.21 & 97 & $32.6 \%$ & $-0.05[-0.34,0.23]$ & & & \\
\hline Rothschild 2012 & -6.35 & 6.07 & 97 & -6.68 & 5.9 & 91 & $31.9 \%$ & $0.05[-0.23,0.34]$ & & & \\
\hline Total $(95 \% \mathrm{Cl})$ & & & 294 & & & 297 & $100.0 \%$ & $-0.10[-0.27,0.06]$ & & & \\
\hline $\begin{array}{l}\text { Heterogeneity: } \mathrm{Chi}^{2}=3.22 \\
\text { Test for overall effect: } \mathrm{Z}=\end{array}$ & $\begin{array}{l}\mathrm{df}=2( \\
.27(\mathrm{P}\end{array}$ & $\begin{array}{l}P=0.2 \\
=0.21 \text { ) }\end{array}$ & $0) ; 1^{2}=$ & $38 \%$ & & & & & $\begin{array}{cc}-1 & -0.5 \\
& \text { Favours [Vortioxetine] }\end{array}$ & Favours [P & lacebo] \\
\hline
\end{tabular}

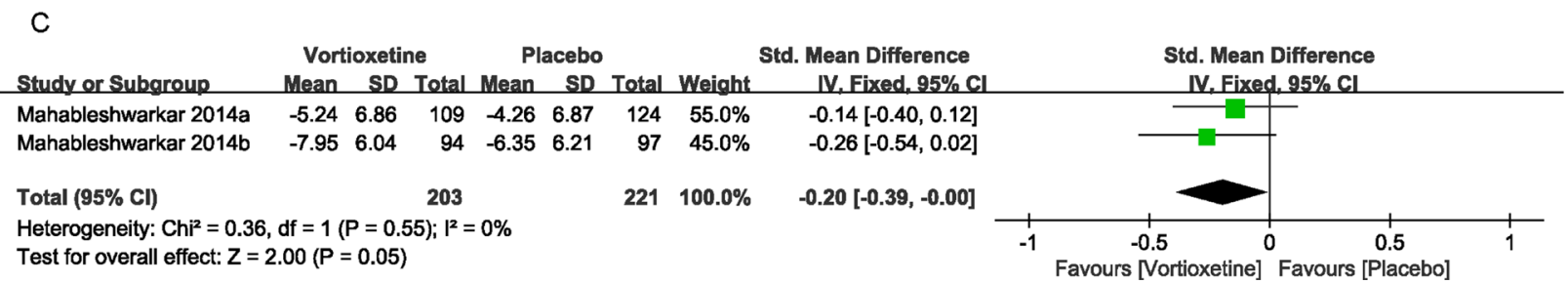

Figure 5 Standardised mean differences and $95 \%$ Cls of the individual studies and the pooled data, comparing the Sheehan Disability Scale scores between the vortioxetine and placebo groups. (A) $2.5 \mathrm{mg} /$ day vortioxetine versus placebo, (B) $5 \mathrm{mg} /$ day vortioxetine versus placebo and (C) $10 \mathrm{mg} /$ day vortioxetine versus placebo. $\mathrm{M}-\mathrm{H}$, Mantel-Haenszel; IV, Inverse Variance.

significant difference regarding the response rates among groups treated with either multiple doses $(2.5,5$ and $10 \mathrm{mg}$ /day) of vortioxetine or a placebo..$^{20}$ Furthermore, the results of our meta-analysis demonstrated no statistically significant difference in the mean change from baseline in total scores on the HAM-A, remission rates, QoL and functional status among the groups. Thus, the results of our meta-analysis were more comprehensive.

Several reasons for these outcomes may have contributed to the negative results. A previous analysis of the FDA database concluded that negative results were commonly seen in anxiolytic agents administered for the treatment of anxiety disorders, including GAD, where less than one-half $(48 \%)$ of the treatment arms were statistically superior to the placebo. ${ }^{41}$ In this case, all anxiolytic agents included in the study are approved for GAD treatment in the USA, but only three out of seven treatment arms were separated from the placebo. Moreover, the results some studies have found that negative results ${ }^{14-16}$ had a higher placebo response rate than those with positive results. ${ }^{13} 42$ Although this correlation has not been established in GAD, it is reasonable to speculate that an elevated placebo response could reduce the treatment effect. Unfortunately, because no positive control was included in our meta-analysis, it is impossible to determine the lack-of-treatment effect. In addition, the racial diversity may have introduced differences in response and remission rates; for example, the studied population of the trial that showed negative results was racially diverse, whereas the population of the trial that showed positive results was almost entirely Caucasian. Hence, the results of the STAR*D study demonstrate that non-Caucasians were significantly less likely to achieve remission. ${ }^{43}$ Furthermore, the mean baseline HAM-A total scores in most of the included studies were relatively high (ranging from 24.5 to 27); inflated baseline HAM-A total scores are a possible consequence of less stringent screening practices. Relative to placebo, vortioxetine treatment, in doses of 10 and $20 \mathrm{mg}$, demonstrated significant improvement in depressive symptoms, however, the RCTs that were studied, in accordance with those included in our metaanalysis, used the optimal doses of 2.5-10 mg. Higher dosages, such as $20 \mathrm{mg}$ or even more, would be more beneficial in anxiety disorders, whereas lower dosages may unaffect anxiety symptoms. However, it is unlikely that any single reason can explain the inconsistent results observed in the vortioxetine for GAD.

Although our meta-analysis did not demonstrate a statistically significant anxiolytic effect of vortioxetine, it did provide the information regarding drug tolerability. Our study found that there was no statistically significant difference for the discontinuation for any reason rates and discontinuation due to AEs rates among groups receiving either multiple doses $(2.5,5$ and $10 \mathrm{mg} /$ day) of vortioxetine compared with placebo, which is similar to the findings of a previous meta-analysis. ${ }^{9} 18$ Thus, the vortioxetine doses were well tolerated, and were associated with similar discontinuation for any reason rates and 
discontinuation due to AEs rates when compared with the placebo.

GAD is associated with significant functional impairment in many areas, including social, occupational and mental consequences; and when combined with physical impairment, together they influence QoL. The effectiveness of GAD treatment for improving QoL and functional outcomes is potentially confounded by the bidirectional relationship of anxiety symptoms and QoL/ functional impairment. This is the first meta-analysis to report prospective assessment of $\mathrm{QoL} /$ functional status impairment for vortioxetine in treatment of patients with GAD. Unfortunately, our meta-analysis of RCTs with patients with GAD showed no significant improvement in the aforementioned aspects after vortioxetine treatment compared with after treatment with the placebo. Our results are not consistent with those of a previous metaanalysis of the effect of vortioxetine treatment on overall functioning in patients with MDD. ${ }^{44}$ The meta-analysis, conducted by Florea et al, demonstrated that vortioxetine, in doses of 5-20 mg for 6/8 weeks, improved overall functioning in patients with MDD. Relative to placebo, vortioxetine treatment, in doses of 10 and $20 \mathrm{mg}$, demonstrated significant improvement in SDS total score and functional remission. However, the RCTs that were studied, in accordance with those included in our meta-analysis, used the optimal doses of 2.5-10 mg. Thus, the reason for the lack of congruence between these two meta-analyses may be the difference in the optimal doses. Meanwhile, a recent meta-analysis of vortioxetine in working patients with $\mathrm{GAD}^{45}$ showed that vortioxetine benefits adult patients who are working and/or pursuing an education. Thus, future research should be directed to provide more RCTs, specifically targeted to individuals with GAD, in order to assess the efficacy of vortioxetine in a larger sample, as well as to define the best therapeutic dosage.

The results of our meta-analysis should be interpreted in light of the following potential limitations. First, we included only four RCTs, which may have influenced the reliability of the results. Second, the duration of each trial included in our meta-analysis was 8 weeks; this is an important issue because patients with GAD typically require long-term pharmacological treatment. We found only one study focusing on long-term relapse prevention, which showed no significant improvement of relapse prevention effect after long-term (maintenance) vortioxetine treatment for GAD compared with placebo. ${ }^{46}$ Furthermore, the systematic review, conducted by Perna $e t$ $a l$, indicated that although some recent data support the long-term efficacy of vortioxetine for GAD and showed a favourable tolerability profile, the conflicting shortterm studies and limited clinical experience recommend its use only as second-line therapy. ${ }^{47}$ In addition, owing to a limited number of studies included in our metaanalysis, we did not compare the onset time between the groups treated with multiple doses of vortioxetine and placebo. Finally, all the included trials were supported by the Takeda Pharmaceutical Company as part of a joint clinical development programme with $\mathrm{H}$. Lundbeck A/S, which may have also influenced the results.

\section{CONCLUSIONS}

In summary, GAD is an illness that is characterised by severe anxiety symptoms, and by diminished functioning and QoL. The challenge for interventions is to achieve improvement of symptoms, but also to enhance patients' functioning ability and QoL. Our comprehensive evaluation of efficacy, safety and impact on QoL provides a critical insight that may be useful for clinicians attempting to thoroughly understand the risk-benefit profiles of vortioxetine treatment for GAD. Vortioxetine did not significantly improve GAD symptoms and QoL as compared with the placebo; nevertheless, it was safe and well tolerated in this patient population. However, our results should be interpreted and translated into clinical practice with caution, owing to the limited number of RCTs included in the present meta-analysis.

Acknowledgements We thank Editage (www.editage.cn) for editing the English text of a draft of this manuscript.

Contributors QB, GH, QY and MY were involved in conceptualisation and design of the study and critical review of the manuscript. $\mathrm{QB}, \mathrm{GH}$ and $\mathrm{MY}$ performed the data extraction. QB, MZ, HC and WG conceived the study and reviewed the manuscript for important intellectual content. All authors approved the final manuscript as submitted.

Funding The authors have not declared a specific grant for this research from any funding agency in the public, commercial or not-for-profit sectors.

Competing interests None declared.

Patient consent for publication Not required.

Provenance and peer review Not commissioned; externally peer reviewed.

Data availability statement Data are available in a public, open access repository. There are no data in this work. Data are available on reasonable request. Data may be obtained from a third party and are not publicly available. No data are available. All data relevant to the study are included in the article or uploaded as online supplementary information.

Open access This is an open access article distributed in accordance with the Creative Commons Attribution Non Commercial (CC BY-NC 4.0) license, which permits others to distribute, remix, adapt, build upon this work non-commercially, and license their derivative works on different terms, provided the original work is properly cited, appropriate credit is given, any changes made indicated, and the use is non-commercial. See: http://creativecommons.org/licenses/by-nc/4.0/.

\section{REFERENCES}

1 American Psychiatric Association. Diagnostic and statistical manual of mental disorders (DSM-5. Fifth Edition. Washington, DC: American Psychiatric Association, 2013.

2 Tyrer P, Baldwin D. Generalised anxiety disorder. The Lancet 2006;368:2156-66.

3 Cuijpers P, Sijbrandij M, Koole S, et al. Psychological treatment of generalized anxiety disorder: a meta-analysis. Clin Psychol Rev 2014;34:130-40.

4 Yonkers KA, Dyck IR, Warshaw M, et al. Factors predicting the clinical course of generalised anxiety disorder. Br J Psychiatry 2000;176:544-9.

5 Ngo CQ, Phan PT, Vu GV, et al. Effects of different comorbidities on health-related quality of life among respiratory patients in Vietnam. JCM 2019;8.

6 Nguyen SH, Nguyen LH, Vu GT, et al. Health-Related quality of life impairment among patients with different skin diseases in Vietnam: a cross-sectional study. Int J Environ Res Public Health 2019;16:pii: E305. 
7 De Berardis D, Olivieri L, Nappi F, et al. Vortioxetine and aripiprazole combination in treatment-resistant obsessive-compulsive disorder. $J$ Clin Psychopharmacol 2017;37:732-4.

8 Lu Y, Ho CS, Mclntyre RS, et al. Effects of vortioxetine and fluoxetine on the level of brain derived neurotrophic factors (BDNF) in the hippocampus of chronic unpredictable mild stress-induced depressive rats. Brain Res Bull 2018;142:1-7.

9 Pae C-U, Wang S-M, Han C, et al. Vortioxetine: a meta-analysis of 12 short-term, randomized, placebo-controlled clinical trials for the treatment of major depressive disorder. J Psychiatry Neurosci 2015;40:174-86.

10 Berhan A, Barker A. Vortioxetine in the treatment of adult patients with major depressive disorder: a meta-analysis of randomized double-blind controlled trials. BMC Psychiatry 2014;14:276.

$11 \mathrm{Fu}$ J, Chen Y. The efficacy and safety of $5 \mathrm{mg} / \mathrm{d}$ Vortioxetine compared to placebo for major depressive disorder: A meta-analysis Psychopharmacology 2015;232:7-16.

12 Tran BX, Ha GH, Vu GT, et al. Indices of change, expectations, and popularity of biological treatments for major depressive disorder between 1988 and 2017: a Scientometric analysis. Int J Environ Res Public Health 2019;16:pii: E2255.

13 Bidzan L, Mahableshwarkar AR, Jacobsen P, et al. Vortioxetine (Lu AA21004) in generalized anxiety disorder: results of an 8-week, multinational, randomized, double-blind, placebo-controlled clinical trial. European Neuropsychopharmacology 2012;22:847-57.

14 Mahableshwarkar AR, Jacobsen PL, Serenko M, et al. A randomized, double-blind, fixed-dose study comparing the efficacy and tolerability of vortioxetine 2.5 and $10 \mathrm{mg}$ in acute treatment of adults with generalized anxiety disorder. Hum Psychopharmacol 2014;29:64-72.

15 Mahableshwarkar AR, Jacobsen PL, Chen Y, et al. A randomised, double-blind, placebo-controlled, duloxetine-referenced study of the efficacy and tolerability of vortioxetine in the acute treatment of adults with generalised anxiety disorder. Int $\mathrm{J}$ Clin Pract 2014;68:49-59.10.1111/ijcp.12328

16 Rothschild AJ, Mahableshwarkar AR, Jacobsen P, et al. Vortioxetine (Lu AA21004) 5mg in generalized anxiety disorder: results of an 8-week randomized, double-blind, placebo-controlled clinical trial in the United States. European Neuropsychopharmacology 2012;22:858-66.10.1016/j.euroneuro.2012.07.011

17 Baldwin DS, Florea I, Jacobsen PL, et al. A meta-analysis of the efficacy of vortioxetine in patients with major depressive disorder (MDD) and high levels of anxiety symptoms. J Affect Disord 2016;206:140-50.

18 Pae C-U, Wang S-M, Han C, et al. Vortioxetine, a multimodal antidepressant for generalized anxiety disorder: a systematic review and meta-analysis. J Psychiatr Res 2015;64:88-98.

19 Yee A, Ng CG, Seng LH. Vortioxetine treatment for anxiety disorder: a meta-analysis study. Curr Drug Targets 2018;19:1412-23.

20 Fu J, Peng L, Li X. The efficacy and safety of multiple doses of vortioxetine for generalized anxiety disorder: a meta-analysis. Neuropsychiatr Dis Treat 2016;12:951-9.

21 Choo CC, Chew PKH, Ho CS, et al. Quality of life in patients with a major mental disorder in Singapore. Front. Psychiatry 2019;9.

22 Lee Y, Rosenblat JD, Lee J, et al. Efficacy of antidepressants on measures of workplace functioning in major depressive disorder: a systematic review. J Affect Disord 2018;227:406-15.

23 Bourland SL, Stanley MA, Snyder AG, et al. Quality of life in older adults with generalized anxiety disorder. Aging Ment Health 2000;4:315-23.

24 Frisch MB. Manual and treatment guide for the quality of life inventory. Minneapolis: National Computer Systems Inc, 1994.
25 Katschnig $\mathrm{H}$. How useful is the concept of quality of life in psychiatry? In: Katschnig $\mathrm{H}$, Freeman $\mathrm{H}$, Sartorius N, eds. Quality of life in mental disorders. Chichester: Wiley, 1997: 10. 337-45.

26 Steven EH. Bridging science and service: A report by the National Advisory Mental Health Council's Clinical Treatment and Services Research Workgroup (NIH Publication No. 99-4353. Rockville: Diane Pub Co, 1999.

27 Zhou X, Keitner Gl, Qin B, et al. Atypical antipsychotic augmentation for treatment-resistant depression: a systematic review and network meta-analysis. IJNPPY 2015;18:pyv060.

28 Mogotsi M, Kaminer D, Stein DJ. Quality of life in the anxiety disorders. Harv Rev Psychiatry 2000;8:273-82.

29 Henning ER, Turk CL, Mennin DS, et al. Impairment and quality of life in individuals with generalized anxiety disorder. Depress Anxiety 2007;24:342-9.

30 Endicott J, Russell JM, Raskin J, et al. Duloxetine treatment for role functioning improvement in generalized anxiety disorder. J Clin Psychiatry 2007;68:518-24.

31 Higgins JPT, Green S. Cochrane Handbook for systematic reviews of interventions version 5.1.0 updated March 2011. Available: http:// www.cochrane-handbook.org [Accessed 13 Nov 2018].

32 Moher D, Liberati A, Tetzlaff J, et al. Reprint--preferred reporting items for systematic reviews and meta-analyses: the PRISMA statement. Phys Ther 2009;89:873-80.

33 Testa MA, Simonson DC. Assessment of quality-of-life outcomes. N Engl J Med 1996;334:835-40.

34 Urbach DR. Measuring quality of life after surgery. Surg Innov 2005;12:161-5.

35 Ware JE, Sherbourne CD. The mos 36-Item short-form health survey (SF-36). Med Care 1992;30:473-83.

36 Sheehan DV, Harnett-Sheehan K, Raj BA. The measurement of disability. Int Clin Psychopharmacol 1996;11:89-95.

37 Higgins J, Thompson S, Deeks J, et al. Statistical heterogeneity in systematic reviews of clinical trials: a critical appraisal of guidelines and practice. J Health Serv Res Policy 2002;7:51-61.

38 Higgins JPTet al. Measuring inconsistency in meta-analyses. BMJ 2003;327:557-60.

$39 \mathrm{RC} \mathrm{H}$, Ong HS, Kudva KG, et al. How to critically appraise and apply meta-analyses in clinical practice. Int J Rheum Dis 2010;13:294-9.

40 Egger M, Smith GD, Schneider M, et al. Bias in meta-analysis detected by a simple, graphical test. BMJ 1997;315:629-34.

41 Khan A, Khan S, Brown WA. Are placebo controls necessary to test new antidepressants and anxiolytics? Int. J. Neuropsychopharm. 2002;5:193-7.

42 Liebowitz MR, Stein MB, Tancer M, et al. A randomized, doubleblind, fixed-dose comparison of paroxetine and placebo in the treatment of generalized social anxiety disorder. J Clin Psychiatry 2002;63:66-74.

43 Trivedi MH, Rush AJ, Wisniewski SR, et al. Evaluation of outcomes with citalopram for depression using measurement-based care in STAR*D: implications for clinical practice. AJP 2006;163:28-40.

44 Florea I, Loft H, Danchenko N, et al. The effect of vortioxetine on overall patient functioning in patients with major depressive disorder. Brain Behav 2017;7:e00622.

45 Christensen MC, Loft H, Florea I, et al. Efficacy of vortioxetine in working patients with generalized anxiety disorder. CNS Spectr 2017.

46 Baldwin DS, Loft H, Florea I. Lu AA21004, a multimodal psychotropic agent, in the prevention of relapse in adult patients with generalized anxiety disorder. Int Clin Psychopharmacol 2012;27:197-207.

47 Perna G, Alciati A, Riva A, et al. Long-Term pharmacological treatments of anxiety disorders: an updated systematic review. Curr Psychiatry Rep 2016;18:23. 